\title{
Creating and Sustaining Interdisciplinary Research Groups
}

\author{
Mary Rezac, Tim Taylor Professor of Chemical Engineering, \\ Kansas State University
}

$\mathrm{M}$ ultidisciplinary research projects are becoming increasingly common within the realm of academic research. Data suggests that more than $50 \%$ of projects funded by NSF and at one major research institution would be included in this category. As academic institutions transition from single PI research projects to teams of researchers from numerous departments and colleges, new issues relating to fund distribution, credit accounting, and team leadership become apparent. Here, we examine the trends in multidisciplinary research projects, the perceived barriers to their success, and recommendations to overcome these barriers.

Interdisciplinary teams develop more complete solutions to societal problems. The National Academy of Engineering has identified 14 critical areas of societal importance that require concerted effort in research, development, and public policy if they are to be successfully addressed. These topics range from making solar energy economical to providing access to clean water to reverse-engineering the brain. The common thread among the topics is that they are interdisciplinary and complex. If solutions to these problems are to be found, engineers must be involved. Yet, engineers working in isolation will almost certainly fail. Rather, they must engage with researchers from agriculture, medicine, public policy, economics, physics, biology, and numerous other fields. This trend toward larger and more complex research problems has been observed for the past two decades.

Funding agencies are shifting their support to interdisciplinary projects.
While complete and precise information about the nature of funding provided by the federal government to interdisciplinary research projects is not immediately available, anecdotal information suggests that funding agencies are shifting their support to interdisciplinary projects. Information relating to the research funding supplied by the National Science Foundation is publically available ${ }^{\mathrm{ii}}$ and can provide some insight into this agencies' tendency in this matter. Figure 1 provides the number and value of awards made by the National Science Foundation from 1980 through 2003. In both cases, if a project was awarded to a single principal investigator, that project was counted in the "individuals" category. If the project had two or more coPIs or a PI with one or more senior personnel identified within the award document, the project was counted in the "team" category. It is interesting to note that the number of awards made to indi- 
viduals during the study period remained roughly constant at about 4500 . In contrast, the number of awards made to teams increased by a factor of four over this same period. At the end of the study

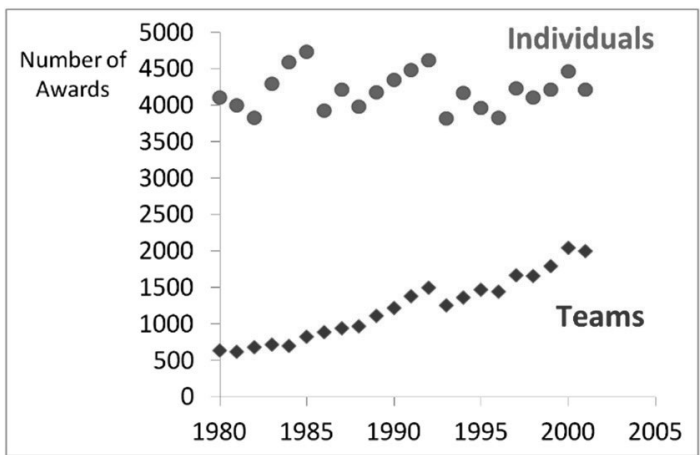

Figure 1: Research projects supported by the National Science Foundation for fiscal years $1980-2003$. Team projects are those with two or more investigators of any title.

period, the number of grants made to individuals remained approximately twice that made to teams.

When the value of the NSF grants is considered (Figure 2), an even more striking argument for the importance of team activities is observed. During the study period, the total value of all awards made by NSF to individuals increased from approximately $\$ 450 \mathrm{M}$ to $\$ 1,100 \mathrm{M}$. Thus, the average value of awards made to individuals increased from $\$ 100,000 /$ grant to
$\$ 245,000 /$ grant. In contrast, the team awards increased at a much faster rate, from $\$ 180 \mathrm{M}$ to $\$ 1,150 \mathrm{M}$ with average awards increasing from about $\$ 300,000 /$ grant to $\$ 575,000 /$ grant.

Thus, it is clear that from NSF funding trends, both the number and value of projects awarded to research teams have increased dramatically in the past decades. If academic research institutions are to compete successfully for these funds, they must support their faculty members and research staff in the development of functional and efficient research teams.

More detailed information is available from an analysis of research completed at the University of North Carolina, Chapel Hill. This information looked at the total research funding and the categorization into projects that included more than one investigator, principal investigator, or lead principal investigator. ${ }^{\text {iii }}$ This data is presented in Figures 3 and 4 . As is the case with many institutions, research funding has increased over the period of $2008-2014$ with a significant uptick in 2010 as a result of ARRA funding. For UNC, the 2014 funding level was approximately $18 \%$ larger

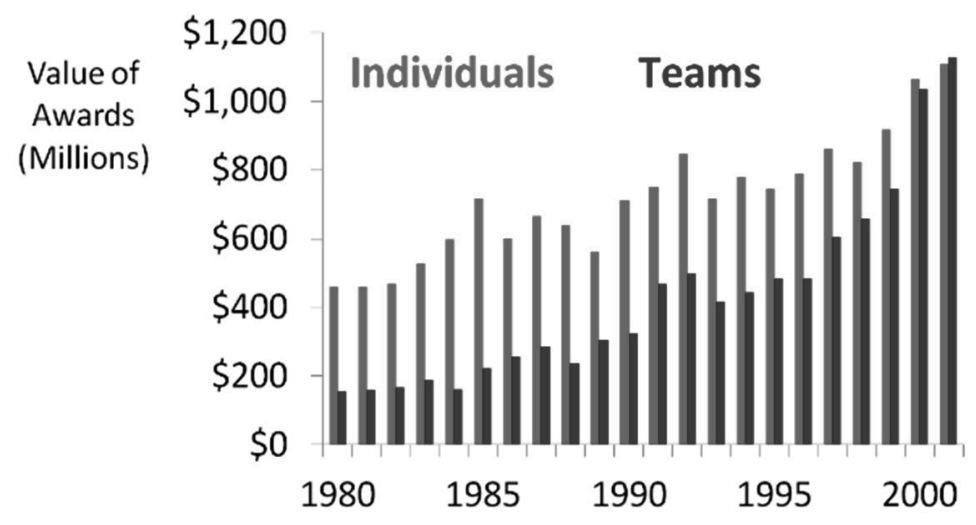

Figure 2: The total value of research projects supported by the National Science Foundation, 1980 - 2003. 
than the 2008 base. Concurrently, the nature of the project leadership teams was also changing. During this entire period, over $55 \%$ of the funded projects at UNC were lead by teams of researchers. Nevertheless, the breadth of the knowledge and expertise of the project leaders appears to be increasing from 2008 to 2014 . In Figure 4, one observes that the percentage of projects with research leaders from more than one department increased from 15 to $45 \%$ and the cross-college collaborations increased from 12 to $25 \%$. Marked increases in both of these categories is noted in 2010 with relatively constant behavior following. This suggests that the broadening of research team leadership may be related to requirements that were made by the federal gov-

\section{Total Funding}

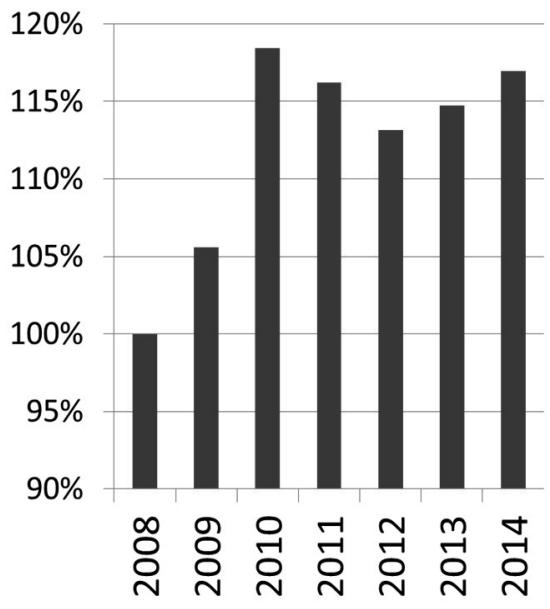

Figure 3: Total research funding at UNC, Chapel Hill, 2008 - 2014. The significant increase in funding in 2010 is the result of additional funding from the American Recovery and Reinvestment Act of 2009. 2008 Funding $=\$ 678 \mathrm{M}$.

ernment as a part of the 2009 ARRA funding initiative. If the ARRA funding was the motivation for this shift, the result seems to have outlived the program.
Analysis of the data indicates that funding agencies are supporting multidisciplinary projects and researchers at successful institutions are shifting to these team-lead projects. Yet, not every researcher has or will navigate the transition to being a productive member of an interdisciplinary team. Why?

There are real and perceived barriers to multi-disciplinary research within academia. While society, funding agencies, and university administrators may be encouraging faculty members to conduct research projects as a member of a multidisciplinary team, that transition can be difficult. In a 2004 study entitled Facilitating Interdisciplinary Research, the National Academy of Engineering concluded that there are multiple barriers to success of these research teams. ${ }^{\text {iv }}$ In a survey of successful academic researchers and re-

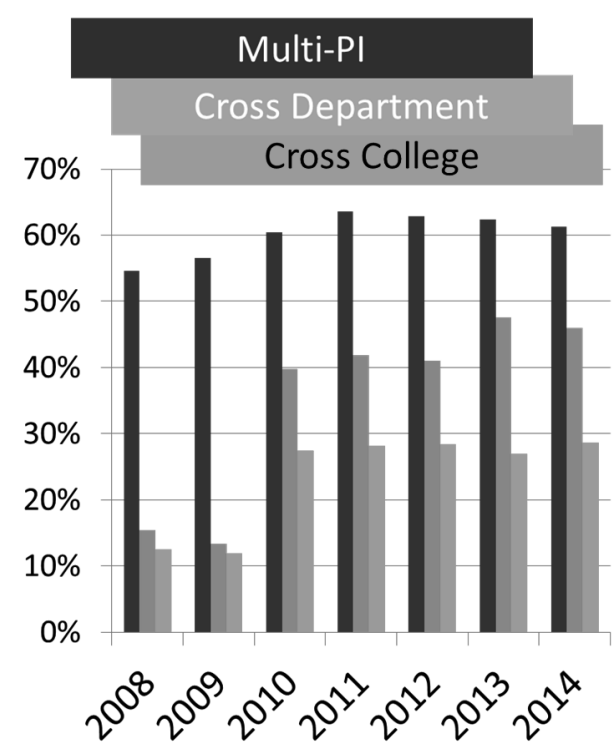

Figure 4: The nature of research funding at UNC, Chapel Hill, 2008 2014. Projects are identified as having multiple investigators (dark blue), investigators from two or more academic departments (grey), and investigators from two or more colleges (green). 


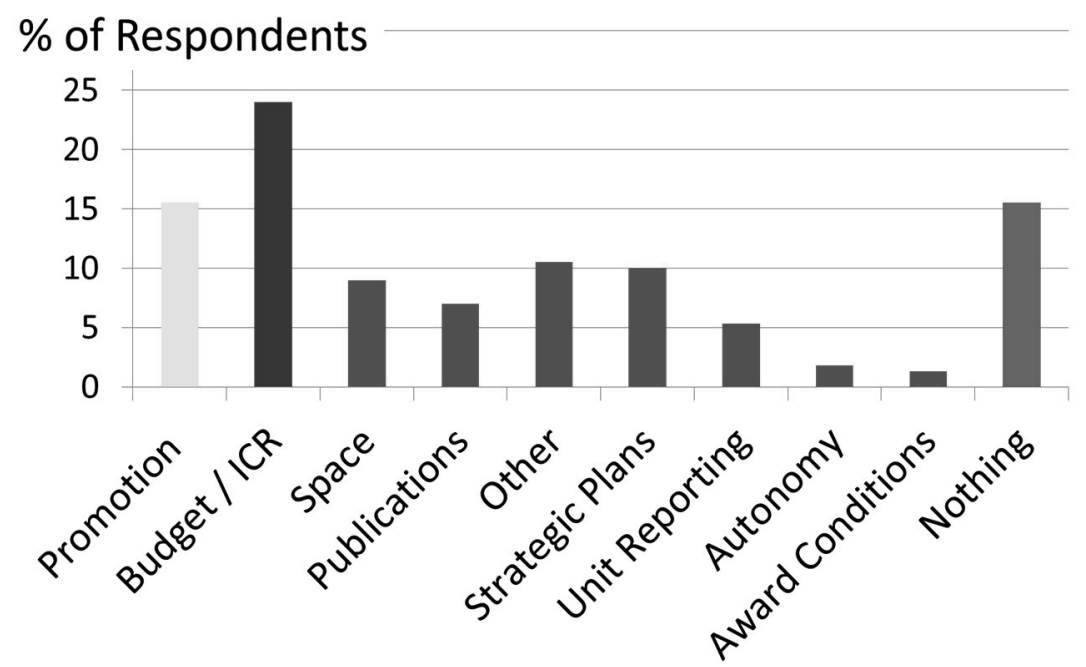

Figure 5: Perceived barriers to multi-disciplinary research projects. Graphics adapted from NAE Facilitating Interdisciplinary Research Report.

search administrators, the items identified in Figure 5 were deemed to be the biggest barriers to success of multi-disciplinary research projects. The categories, from left to right, are more completely described as: concerns with receiving appropriate credit in promotion and tenure decisions, concerns relating to control of the research budget and/or allocation of indirect cost returns, lack of adequate space to complete the project, concerns with receiving appropriate credit for multi-author publications, other - five separate items each of which received no more than $3 \%$ of the votes, concerns with lack of alignment of project with unit strategic plans, concerns with each contributing unit receiving appropriate credit for activity, concerns with loss of individual researcher autonomy, concerns with receiving appropriate credit for award consideration, and finally, 'nothing' indicating that the respondent felt that there were no major barriers to interdisciplinary research activities.

Of the 14 categories evaluated, only three individually received more than $15 \%$ of the votes. Combined, the three top scorers received nearly $55 \%$ of all votes. These are (1) budget/indirect cost return, (2) nothing, and (3) promotion. Perhaps reassuringly, 'nothing' was the second most common result. This suggests that in this 2003 survey, faculty members had already come to the conclusion that there were few actual barriers to team research success. As the number and magnitude of team projects has continued to increase in the past decade, we can only assume that this category will continue to dominate the feelings of faculty researchers.

It is interesting to note that the majority of the concerns relate to allocation of credit whether it be for considerations of promotion and tenure, publications, awards, or unit productivity. It would seem that active work to create a university culture that promotes and rewards members of interdisciplinary teams could go a long way to overcome these fears.

The NAE study also surveyed principal investigators on what recommendations they would make to peers to facilitate interdisciplinary research projects. Results of this survey are summarized in 


\section{$\%$ of Respondents}

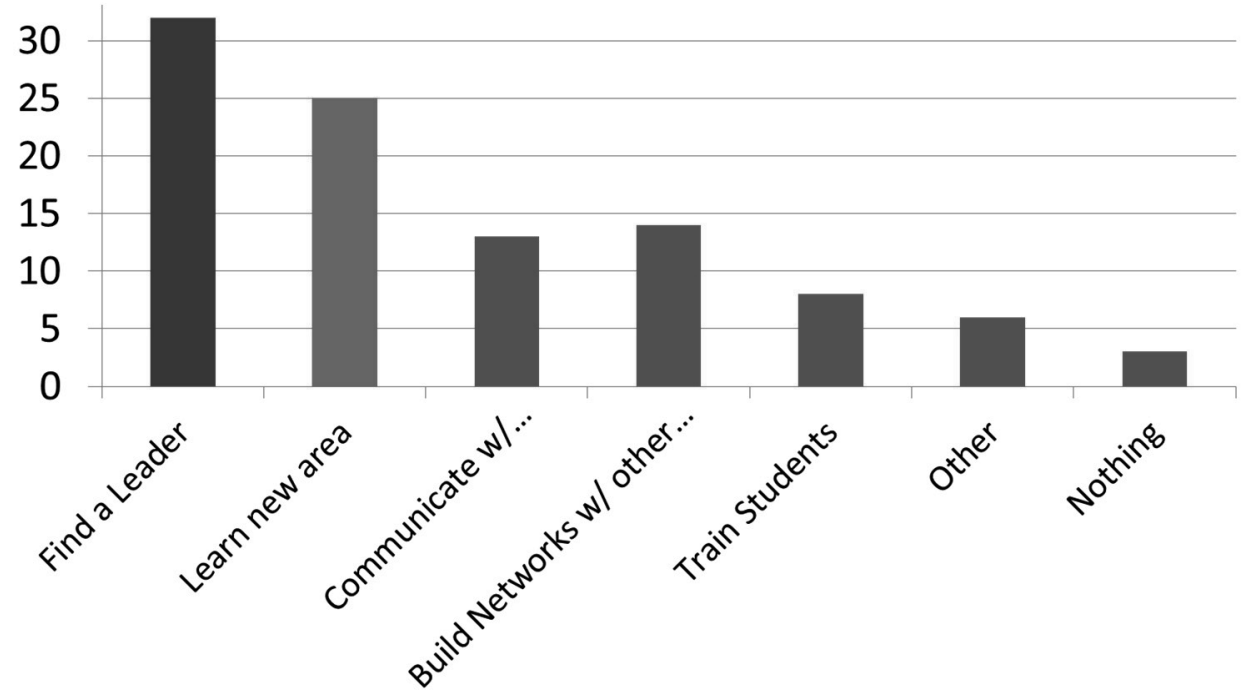

Figure 6: PI recommendations to peers on the single most important step they can make to facilitate multi-disciplinary research project success. Graphics adapted from NAE Facilitating Interdisciplinary Research Report.

Figure 6. Again, the y-axis indicates the frequency of response while the $x$-axis provides the dominant category. From left to right, the categories were: find an individual willing and capable of leading the team project, learn about the new scientific area into which you are entering, communicate with others outside your field to identify potential collaborators, build networks with others outside your field to find potential collaborators, train students in the new topical area, other five categories none of which exceeded $2 \%$ of the vote, nothing/no recommendation. Based on these options, PIs believed that the single action to promote success was identification of a team leader.

The leaders identified are not simply the individual with the most in-depth knowledge of the subject area. Indeed, in these multidisciplinary projects, several team members may have equally deep, but differently focused subject area expertise. Rather, the leader that is required is an individual with sufficient subject area expertise to garner the respect of her or his peers while simultaneously having the managerial, organizational, motivational skills to identify, recruit, promote, facilitate, and finance a research team. These skills can be at odds with the elements of success that have been promoted throughout a faculty member's independent research career and, thus, are not always naturally present in any given member of the research team. Furthermore, when one considers the reward system historically utilized by academic institutions, one can understand why few have voluntarily migrated to this position. Indeed, when academics are rewarded on number (publications, invited seminars, students advised, researcher dollars received), activities which detract from these metrics are understandably minimized. Faculty members are clear in their analysis that leadership of interdisciplinary teams has negative consequences on short-term productivity. Obviously, individuals who have short-term 
evaluations (like promotion and tenure) will avoid these leadership positions.

That leaves only the camp of full professors in a position to effectively lead large, multi-disciplinary research teams. Yet, now 10 or more years into their careers, they may have received little or no training on how to succeed in this role. Ah, the quandary.

If we are to transition to this new era of interdisciplinary research team success, our organizations must develop mechanisms for identify, training, and truly rewarding team leaders. The options on the type of rewards are as numerous as the number of team leaders identified. Yet, a few mechanisms are provided for consideration: (1) provide an indirect cost return system that financially rewards the leader of a team project; (2) provide central support for personnel to support large, team projects with the completion of the reports and data collection frequent in these projects; (3) provide central support for evaluation of large, team projects; (4) develop and finance a university-wide research award that focuses on success as a team leader; (5) identify faculty members at all ranks with the skills and inclination to be successful team leaders - provide members of this group with mentoring, and local and external professional development training to improve their skills; (6) recognize the role of team leader in publicity and marketing materials. These are but a few of the ideas of how one might recognize and support those faculty members who have and will serve in leadership roles within multidisciplinary projects. No matter how it is accomplished, it is imperative that individuals who have voluntarily accepted the leadership role and have been successful in that role be rewarded, recognized, and encouraged to continue in this pattern. Supporting a good team leader is much easier than developing a new one.

Acknowledgements: I thank Mabel Rice for her kind invitation to be a part of the 2015 Merrill Conference and Evelyn Haaheim for making the experience so enjoyable. Several of these opinions are a result of extensive discussions with Loretta Johnson and Stacy Hutchinson at K-State. I am thankful to them for taking time to talk to me about these issues.

\section{Cited Works}

i W. Perry, et al., Grand Challenges for Engineering, The National Academies Press, 2008, available at www.engineeringchallenges.org

ii www.nsf.gov/awardsearch

iii Research.unc.edu/about/facts-rankings/research-funding Note, it is not clear precisely how 'research funding' has been defined. It appears to include research expenditure data but may be based on research awards.

iv Committee on Facilitating Interdisciplinary Research, Facilitating Interdisciplinary Research, National Academy of Sciences, National Academy of Engineering, Institute of Medicine, 2004, ISBN: 978-0-039-09435-1 